\title{
Correlation Between Maximum Inspiratory Pressure and Hand-Grip Force in Healthy Young and Middle-Age Individuals
}

\author{
Ioannis D Efstathiou PT, Irini P Mavrou MD, and Konstantinos E Grigoriadis PT MSc
}

\begin{abstract}
BACKGROUND: This study aimed to examine the relationship between hand-grip force and maximum inspiratory pressure $\left(P_{I m a x}\right)$ in healthy young and middle-age individuals. METHODS: All individuals underwent assessment of inspiratory muscle strength by maximum inspiratory pressure using a U-type water manometer and evaluation of hand-grip force by a hydraulic hand dynamometer. RESULTS: The correlation of $P_{\text {Imax }}$ and hand-grip force was strong $(r=0.76)$. A multilinear regression model was built to investigate the ability of various parameters, such as hand-grip force, sex, and body mass index measurements, to predict $P_{\text {Imax }} \cdot P_{\text {Imax }}$ can be accurately predicted by $80 \%(r=0.76)$ with a simple equation of easily evaluable factors, such as hand-grip force, body mass index, and sex. CONCLUSION: The results showed significant correlation between hand flexors' force and strength of inspiratory muscles in healthy individuals. This appears to be an easy way to evaluate the results indirectly and can help to assess the relationship between hand flexor and inspiratory muscle capacity, especially the diaphragm. Our study should be viewed as a hypothesis-generating one, and further studies are required in the population of critically ill or difficult-to-wean patients. (ClinicalTrials.gov registration NCT02423616.) Key words: hand grip; strength; maximum inspiratory pressure; respiratory assessment; healthy subjects. [Respir Care 2016;61(7):925-929. ( ) 2016 Daedalus Enterprises]
\end{abstract}

\section{Introduction}

Maximum inspiratory pressure $\left(\mathrm{P}_{\mathrm{Imax}}\right)$ is the amount of negative pressure a patient is able to generate when trying to inhale. It indicates the muscle strength and ventilatory reserve. The patient's ability to reverse atelectasis, to cough effectively, and to manage airway secretions correlates with $\mathrm{P}_{\text {Imax }} \cdot{ }^{1-3} \mathrm{P}_{\text {Imax }}$ is the most common way to assess the force of inspiratory muscles; it reflects the combined forcegenerating capacity of the inspiratory muscles during a brief, quasi-static contraction (Mueller maneuver). ${ }^{4}$ This

\footnotetext{
Mr Efstathiou and Mr Grigoriadis are affiliated with the Department of Physical Therapy, Attikon University Hospital, Athens, Greece. Dr Mavrou is affiliated with the Second Department of Critical Care Medicine, National and Kapodistrian University of Athens-School of Medicine, Attikon University Hospital, Athens, Greece.
}

The authors have disclosed no conflicts of interest.

Correspondence: Efstathiou D Ioannis PT, 1 Rimini Street, Athens 12462, Greece. E-mail: johnefsta@yahoo.gr.

DOI: $10.4187 /$ respcare.04319 pressure reflects equally well the force of the peripheral muscles. ${ }^{5,6}$ Medical Research Council subscore key muscles (shoulder abductors and elbow flexors, wrist extensors, hip flexors, knee extensors, ankle dorsiflexors) already have been correlated with $\mathrm{P}_{\text {Imax }}$. Additionally, $\mathrm{P}_{\text {Imax }}$ is a surrogate parameter for the assessment of ICU-acquired weakness. ${ }^{7,8}$ Normal values of $\mathrm{P}_{\text {Imax }}$ are $\geq-60 \mathrm{~cm} \mathrm{H}_{2} \mathrm{O}$. $\mathrm{P}_{\text {Imax }}$ values of $<-20 \mathrm{~cm} \mathrm{H}_{2} \mathrm{O}$ predict impending respiratory failure. ${ }^{9}$

Hand-grip measurement is easier and faster, requires minimal equipment, and can be performed in one step, whereas $\mathrm{P}_{\mathrm{Imax}}$ measurement requires 3 trials and singleuse equipment and is difficult to administer. $\mathrm{P}_{\text {Imax }}$ can be underestimated in the existence of upper airway pathology or submaximal effort. This latter factor can happen frequently, since the $\mathrm{P}_{\text {Imax }}$ maneuver carries important inconveniences. The patient should coordinate well with the technician, should be taught about the technique, and should also have functional facial muscles. Among the voluntary techniques, the assessment of esophageal pressure during forced inhalation is considered the most accurate test of overall inspiratory strength. ${ }^{7}$ This hypothesis was initially investigated in older adults. ${ }^{10,11}$ The current study attempts 
to validate the previous findings in young and middle-aged individuals. It may also serve as a reference research project for future studies performed in the ICU setting.

Recent studies show that besides $\mathrm{P}_{\text {Imax }}$, sniff pressure is an additional way of measuring the negative pressure of the diaphragm. In some cases, its use is preferred, but it is not always possible and does not affect all difficult situations. ${ }^{12,13}$ The aim of this study was the investigation of (1) the correlation between $P_{\text {Imax }}$ and hand-grip force and (2) the ability of various parameters, such as hand-grip force, sex, and body mass index (BMI) measurements, to predict $\mathrm{P}_{\text {Imax }}$.

\section{Methods}

\section{Ethics, Population}

The study was approved by the hospital's Ethics Committee (approval 03-13, February 2, 2015). Informed consent was obtained from all participants before the commencement of the study.

The study population consisted of healthy volunteers from the hospital staff of the Physical Therapy Department, the ICU, and the Cleaning Services of Attikon University Hospital. All subjects were between 20 and 65 y old. They had no prior respiratory or muscular pathology, and their $\mathrm{P}_{\text {Imax }}$ had not been previously measured. ${ }^{14}$ Exclusion criteria were age $<20$ y old; pregnancy; official diagnosis of lung disease, such as COPD; BMI $\mathrm{kg} / \mathrm{m}^{2}$ $>40$; known preexisting causes of neuromuscular weakness; and median entrapment neuropathy, such as carpaltunnel syndrome.

\section{Study Design}

All subjects who fulfilled the inclusion criteria received the 2 basic tests: (1) the test of hand-grip force and (2) the test of maximum inspiratory pressure. The sequence of the tests was alternated, and the randomization of alternation was accomplished by coin flipping.

In order to measure $\mathrm{P}_{\text {Imax }}$, we constructed a U-shaped manometer (Fig. 1). We took a pipe with a diameter of $1 \mathrm{~cm}$, which was calibrated in $\mathrm{cm}$ using a measuring tape and was filled with distilled water. The structure was $2.5 \mathrm{~m}$ high, and the level of the water was at $1.3 \mathrm{~m}$. The mouthpiece at the edge of the tube was replaced in each volunteer for hygiene reasons. The whole structure was stabilized on a long and narrow wooden surface, such as a metal trolley IV pole, in order to be portable. The measurement of $\mathrm{P}_{\text {Imax }}$ included 3 efforts, and the strongest was recorded. The precision for the $\mathrm{U}$-shaped manometer by bibliographic evidence is $\leq 5 \% .{ }^{15}$

A hydraulic gauge (Baseline Hydraulic Dynamometer 7, Medline Industries, Mundelein, Illinois) was used to

\section{QUICK LOOK}

\section{Current knowledge}

Functionality of the respiratory system has been correlated with maximum inspiratory pressure $\left(\mathrm{P}_{\mathrm{Imax}}\right)$ and with the force of peripheral muscles (Medical Research Council subscore) separately. These correlations are useful to assess ICU neuromyopathy.

\section{What this paper contributes to our knowledge}

In a group of healthy subjects, the correlation between hand-flexors force (hand-grip force) and strength of inspiratory muscles $\left(\mathrm{P}_{\text {Imax }}\right)$ was significant. This may be useful in cases where the evaluation of $\mathrm{P}_{\text {Imax }}$ is difficult. This study is preliminary and needs to be confirmed in ICU subjects.

measure the hand-grip force (Fig. 2). The precision by the specifications of the dynamometer from the manufacturer is $\leq 10 \%$. The strongest effort was recorded and remained recorded until the next attempt. Each subject was in a comfortable sitting position, with the shoulders in neutral rotation and the elbow flexed at $90^{\circ}$. The resting time between the $\mathrm{P}_{\text {Imax }}$ test and hand-grip force test (or the opposite) was $\geq 5 \mathrm{~min}$. In every measurement, volunteers were verbally encouraged to give their best effort by the command: "Go, go, go." 16

\section{Statistics}

Descriptive statistics are presented as means $\pm \mathrm{SD}$, medians and interquartile ranges, or percentages when appropriate. The Shapiro-Wilk test was used to determine whether the variables of interest followed a normal distribution. We estimated that 38 subjects were needed to provide a power of $90 \%$ to determine a moderate association, assuming a correlation coefficient of $0.50(\alpha=0.05,2$-sided $)$. We increased the necessary sample by $20 \%$ (to 48 subjects) to account for possible subject drop-outs (unwillingness or failure to cooperate in the study).

Because maximum inspiratory pressure was normally distributed $(P=.60)$, whereas hand grip force was not $(P=.01)$, their association was evaluated by the nonparametric Spearman's correlation coefficient and the respective $P$ value. Spearman's rho of $<0.20$ is considered to indicate very weak correlation, $0.21-0.40$ indicates weak correlation, $0.41-0.60$ indicates moderate correlation, $0.61-0.80$ indicates strong correlation, and $\geq 0.81$ indicates very strong correlation. Linear regression analysis was also performed to evaluate the variables independently associated with maximum inspiratory pressure. 


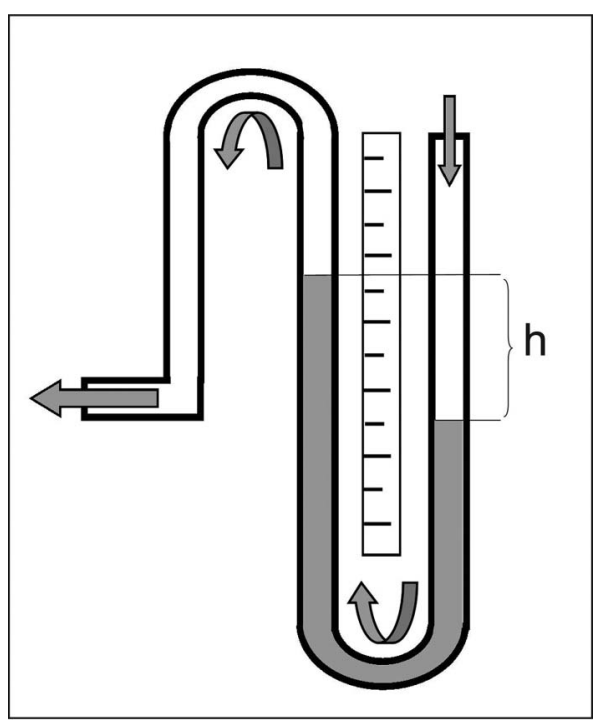

Fig. 1. Schematic depiction of the device built to measure $P_{\text {Imax }}$. The elevation of difference $(h)$ is measured in $\mathrm{cm} \mathrm{H}_{2} \mathrm{O}$.

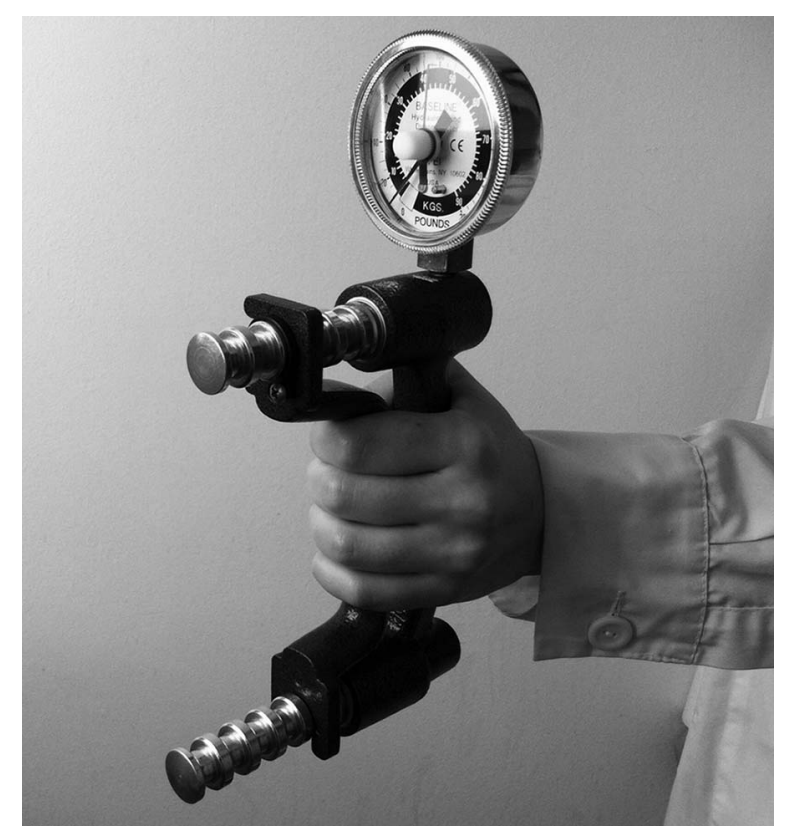

Fig. 2. The hydraulic gauge for hand-grip force, measurement in $\mathrm{kg}$.

Covariates included in the univariable and the multivariable models were either binomial (sex, physical exercise, smoking status) or continuous variables (age, weight, height, BMI, hand-grip force). In the univariable models, a criterion of $P \leq .10$ was used to identify candidate predictors. Then we fitted a multivariable model and used a backwards selection procedure to eliminate those variables not significant in the multivariable framework. We used a criterion of $P \leq .05$ for determining which ones to eliminate. The beta coefficients derived from linear regres- sion analysis are presented with 95\% CIs and the respective $P$ values. For hypothesis testing, a probability level of $<.05$ was considered as statistically significant. All statistical tests were 2-sided. Stata (StataCorp, College Station, Texas) was used for all statistical analyses.

\section{Results}

The characteristics of the study population are shown in Table 1. Twenty-four subjects were initially assessed with hand-grip force and 24 with $\mathrm{P}_{\text {Imax }}$. The distribution of ages is shown in Table 1. Almost half of the volunteers (46\%) were smokers (use of 10-30 cigarettes/d). Male smokers smoked fewer cigarettes, but the difference was not statistically significant $(P=.62)$.

Mean values of $\mathrm{P}_{\text {Imax }}$ in women were $25 \%$ lower than in men $(P<.001)$. The mean value of $\mathrm{P}_{\text {Imax }}$ was $6 \%$ higher in smokers than in non-smokers but without a statistically significant difference $(P=.47)$. The volunteers who exercised (at least once per week with moderate- to maximum-intensity exercise) seemed to have a slight increase in the average $\mathrm{P}_{\text {Imax }}(7 \%)$ but also without statistical significance $(P=.45)$.

Several independent variables seem to correlate with $\mathrm{P}_{\text {Imax }}$, such as age, sex, height, BMI, and hand-grip force. Among them, height and hand-grip force had strong correlation with $\mathrm{P}_{\text {Imax }}$, whereas age, sex, and BMI had weak correlation with $\mathrm{P}_{\text {Imax }}$. The details are presented in Table 2.

The multilinear regression model analysis showed that the factors associated strongly with the $\mathrm{P}_{\text {Imax }}$ were handgrip force, sex, and BMI with beta factors 1.032, 0.386, and 0.117 , respectively. The strongest association was found with hand-grip force.

Spearman's rho correlation coefficient between handgrip force and $\mathrm{P}_{\text {Imax }}$ was 0.76 , indicating strong correlation of parameters (Fig. 3). Thus, hand grip force, sex, and BMI had the higher power.

The healthy volunteers studied provided valuable information about $\mathrm{P}_{\text {Imax }}$ and hand-grip force correlation (correlation coefficient $r=0.76$ ). The strong correlation suggests that $\mathrm{P}_{\text {Imax }}$ can be predicted from hand-grip force and vice versa. The estimation can be done using the formula, $\mathrm{P}_{\text {Imax }}=-51.6+22 \times \operatorname{sex}+0.685 \times \mathrm{BMI}+2.459 \times$ hand-grip force, where sex $=1$ for men and 2 for women.

\section{Discussion}

The findings of the study can be summarized as follows: (1) the correlation between hand-grip force and $\mathrm{P}_{\text {Imax }}$ seems to be strong in healthy individuals, and (2) the value of $\mathrm{P}_{\text {Imax }}$ can be predicted by important parameters, such as sex, BMI, and hand-grip force. Hand-grip force was shown to be a simple tool in assessing the respiratory system of 
Correlation Between $\mathrm{P}_{\text {Imax }}$ And Hand-Grip Force

Table 1. Characteristics of the Study Population

\begin{tabular}{|c|c|c|c|}
\hline & Males $(n=26)$ & Females $(n=22)$ & Total $(N=48)$ \\
\hline Age, mean $\pm \mathrm{SD}$; median (IQR) y & $38.3 \pm 8.4 ; 40(34-44)$ & $32.6 \pm 10.3 ; 31(23-40)$ & $35.7 \pm 9.6 ; 37(25-44)$ \\
\hline Weight, mean $\pm \mathrm{SD}$; median (IQR) $\mathrm{kg}$ & $87.4 \pm 15.7 ; 84(75-95)$ & $69.4 \pm 17.1 ; 68.5(54-80)$ & $79.1 \pm 18.5 ; 80(67.5-92.5)$ \\
\hline Height, mean $\pm \mathrm{SD}$; median (IQR) $\mathrm{cm}$ & $178 \pm 6 ; 178(174-180)$ & $166 \pm 8 ; 166(160-170)$ & $172 \pm 9 ; 174(165-178)$ \\
\hline Physical exercise, $n(\%)^{*}$ & $9 / 26(35)$ & $5 / 22(23)$ & $14 / 48(29)$ \\
\hline Current smokers, $n(\%)$ & $11 / 26(42)$ & $11 / 22(50)$ & $22 / 48(46)$ \\
\hline $\mathrm{P}_{\text {Imax }}$, mean $\pm \mathrm{SD}$; median (IQR) $\mathrm{cm} \mathrm{H}_{2} \mathrm{O}$ & $114.8 \pm 22.7 ; 112(102-124)$ & $86.2 \pm 27.7 ; 86(68-102)$ & $101.7 \pm 28.7 ; 102(84-120)$ \\
\hline $\mathrm{HGF}$, mean $\pm \mathrm{SD}$; median (IQR) kg & $51.0 \pm 7.2 ; 51.5(46-58)$ & $31.2 \pm 6.4 ; 31.25(26-34)$ & $41.9 \pm 12.1 ; 41(32-52.5)$ \\
\hline $\mathrm{BMI}$, mean $\pm \mathrm{SD}$; median (IQR) $\mathrm{kg} / \mathrm{m}^{2}$ & $27.7 \pm 4.4 ; 25.8(25.0-30.4)$ & $24.9 \pm 5.2 ; 25.3(20.7-29.5)$ & $26.4 \pm 4.9 ; 25.5(23.0-29.8)$ \\
\hline \multicolumn{4}{|c|}{$\begin{array}{l}\text { P Physical exercise is presented as a binomial variable (subjects who exercised at least once per week with moderate- to maximum-intensity exercise vs all others). } \\
\text { IQR = interquartile range } \\
\text { PImax }_{\text {Imaximum inspiratory pressure }} \\
\text { HGF = hand-grip force } \\
\text { BMI = body mass index }\end{array}$} \\
\hline
\end{tabular}

Table 2. Parameters Associated With Maximum Inspiratory Pressure: Linear Regression Analysis Results

\begin{tabular}{|c|c|c|c|c|c|c|}
\hline \multirow{2}{*}{ Variables } & \multicolumn{3}{|c|}{ Univariable Analysis } & \multicolumn{3}{|c|}{ Multivariable Analysis } \\
\hline & Coef. & $95 \% \mathrm{CI}$ & $P$ & Coef. & $95 \% \mathrm{CI}$ & $P$ \\
\hline Age, y & 0.55 & -0.31 to +1.42 & .21 & NA & NA & NA \\
\hline Weight, kg & 0.94 & $0.57-1.30$ & $<.001$ & NA & NA & NA \\
\hline Height, cm & 206 & $132-279$ & $<.001$ & NA & NA & NA \\
\hline Physical exercise* & 6.9 & -11.5 to +25.4 & .45 & NA & NA & NA \\
\hline Current smoking & 0.78 & -16.1 to +17.7 & .93 & NA & NA & NA \\
\hline Sex & 28.6 & $13.9-43.2$ & $<.001$ & -23.0 & -41.6 to -4.4$)$ & .017 \\
\hline $\mathrm{HGF}, \mathrm{kg}$ & 1.81 & $1.35-2.27$ & $<.001$ & 2.60 & $1.83-3.38$ & $<.001$ \\
\hline BMI, $\mathrm{kg} / \mathrm{m}^{2}$ & 2.43 & $0.85-4.01$ & .003 & NA & NA & NA \\
\hline \multicolumn{7}{|c|}{$\begin{array}{l}\text { In the univariable analyses, weight, height, sex, hand-grip force, and body mass index were statistically significantly positively associated with the maximum inspiratory pressure. In the multivariable } \\
\text { model, only sex and hand-grip force were independently associated with the maximum inspiratory pressure. The } \mathrm{R}^{2} \text { statistic of the model was } \sim 63 \% \text {, meaning that the model fits our data well and } \\
\text { that hand-grip force and sex explain } 63 \% \text { of the response variable (maximum inspiratory pressure) variation. } \\
\text { * Physical exercise is analyzed as a binomial variable (ie, subjects who exercised at least once per week with moderate- to maximum-intensity exercise vs all others). } \\
\text { Coef. = beta coefficient } \\
\text { NA = not applicable } \\
\text { HGF = hand-grip force } \\
\text { BMI = body mass index }\end{array}$} \\
\hline
\end{tabular}

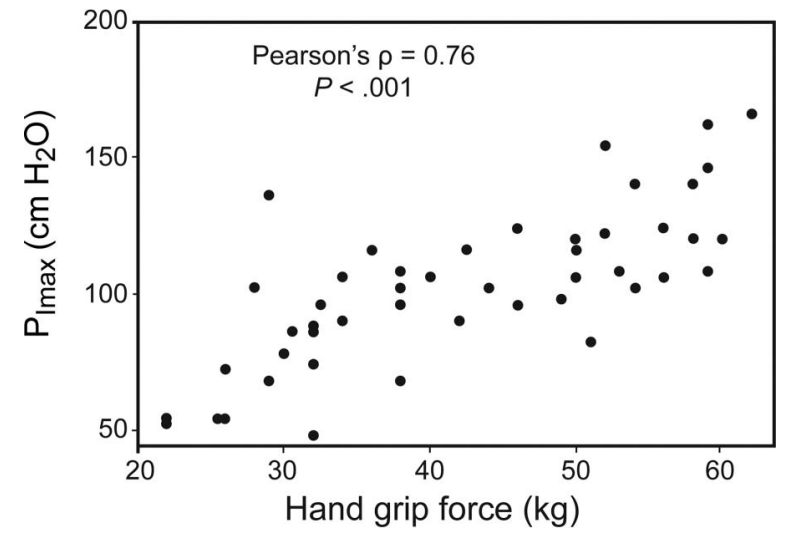

Fig. 3. Correlation of hand-grip force $(\mathrm{kg})$ and $\mathrm{P}_{\operatorname{Imax}}\left(\mathrm{cm} \mathrm{H}_{2} \mathrm{O}\right)$. the study population as well as useful in predicting $\mathrm{P}_{\mathrm{Imax}}$. The above prediction was based on the strong correlation between hand-grip force and $\mathrm{P}_{\text {Imax }}$. Sex and BMI have a special role in this correlation, and this leads to a high probability that the musculature affects the functionality of the respiratory system. The association between the function of the peripheral muscle groups and respiratory muscles was introduced by previous studies showing that hand-grip force and quadricep function, ${ }^{17}$ as well as peripheral muscles and diaphragm function, ${ }^{5}$ correlate strongly ( $\mathrm{r}$ values of 0.75 and 0.68 , respectively).

It is noted that one study concluded that the hand-grip force can be used to evaluate the progress of COPD in elderly subjects, ${ }^{18}$ whereas 2 other studies described the hand-grip force as a valuable, functional prognostic indi- 
cator for assessing the respiratory system of ICU patients. The first study concluded that the hand-grip force can be used as an independent prognostic factor of weaning from mechanical ventilation, ${ }^{19}$ and the second one concluded that the hand-grip force can be used as a factor for predicting re-intubation following extubation. ${ }^{20}$ In summary, the hand-grip force has been proposed as a useful indicator of the patient's performance.

Contrary to these findings, a study of elderly people ${ }^{10}$ concluded that the correlation between hand-grip force and diaphragm $\left(\mathrm{P}_{\text {Imax }}\right)$ is low ( $\mathrm{r}$ values of 0.21 in men and 0.19 in women); it remains unclear whether this can be attributed to a different rate of aging of respiratory muscles as compared with the peripheral muscles.

Hand-grip force is the first force indicator for an ICU patient and one of the first actions that a patient is asked to perform while recovering from sedation. It is easy to use, fast, and inexpensive and gives instant information about the muscular and mental status of the patient under evaluation. $\mathrm{P}_{\operatorname{Imax}}$ is a useful indicator for monitoring the progress of the respiratory system, especially in neuromuscular diseases. However, $\mathrm{P}_{\text {Imax }}$ measurement requires patient cooperation and occasionally can be a difficult maneuver. Additionally, during the measurement, difficulties might exist, such as Bell palsy, lip injuries, jaw fractures, etc. In these cases, measurement of $\mathrm{P}_{\text {Imax }}$ through hand-grip force is quite helpful.

Our study has several limitations. The most important is the lack of generalizability of our findings, since our studied subjects were intentionally chosen to be healthy and, thus, not representative of the disease burden carried by the average ICU patient. However, we hypothesize that hand-grip force may provide information for the evaluation of the respiratory system in ICU patients. The results of this study are promising, and further studies need to be performed in ICU patients in order to establish whether the hand-grip force can be used for predicting $\mathrm{P}_{\text {Imax }}$ and evaluating the respiratory system of this group.

\section{Conclusions}

Among healthy individuals, there is a strong correlation between hand-grip force and maximum inspiratory pressure. Further studies should attempt to validate this association in critically ill patients and explore its utility in predicting important clinical outcomes, such as successful weaning.

\section{ACKNOWLEDGMENTS}

We thank intensivist Petros Kopterides (University of Pittsburgh) and clinical epidemiologist Stefanos Bonovas for valuable corrections to improve the quality of the text and the statistical analysis.

\section{REFERENCES}

1. Jardim JR, Camelier A, Dal Corso S, Rodrigues JE. Strength and endurance of the respiratory and handgrip muscles after the use of flunisolide in normal subjects. Respir Med 2007;101(7):1594-1599.

2. Toussaint M, Boitano LJ, Gathot V, Steens M, Soudon P. Limits of effective cough-augmentation techniques in patients with neuromuscular disease. Respir Care 2009;54(3):359-366.

3. White GC. Basic clinical lab competencies for respiratory care: an integrated approach. Clifton Park, New York: Delmar; 5th edition, 2013:83.

4. Larson JL, Covey MK, Vitalo CA, Alex CG, Patel M, Kim MJ. Maximal inspiratory pressure: learning effect and test-retest reliability in patients with chronic obstructive pulmonary disease. Chest 1993;104(2):448-453.

5. Tzanis G, Vasileiadis I, Zervakis D, Karatzanos E, Dimopoulos S, Pitsolis T, et al. Maximum inspiratory pressure, a surrogate parameter for the assessment of ICU-acquired weakness. BMC Anesthesiol 2011;11:14

6. Evans JA, Whitelaw WA. The assessment of maximal respiratory mouth pressures in adults. Respir Care 2009;54(10):1348-1359.

7. Martínez-Llorens J, Ausín P, Roig A, Balañá A, Admetlló M, Muñoz L, Gea J. Nasal inspiratory pressure: an alternative for the assessment of inspiratory muscle strength? Arch Bronconeumol 2011;47(4): 169-175.

8. Prigent H, Lejaille M, Falaize L, Louis A, Ruquet M, Fauroux B, et al. Assessing inspiratory muscle strength by sniff nasal inspiratory pressure. Neurocrit Care 2004;1(4):475-478.

9. Black LF, Hyatt RE. Maximal respiratory pressures: normal values and relationship to age and sex. Am Rev Respir Dis 1969;99(5):696-702.

10. Berry JK, Vitalo CA, Larson JL, Patel M, Kim MJ. Respiratory muscle strength in older adults. Nursing Res 1996;45(3):154-159.

11. Bahat G, Tufan A, Ozkaya H, Tufan F, Akpinar TS, Akin S, et al. Relation between hand grip strength, respiratory muscle strength and spirometric measures in male nursing home residents. Aging Male 2014; 17(3):136-140.

12. Ju C, Liu W, Chen RC. Twitch mouth pressure and disease severity in subjects with COPD. Respir Care 2014;59(7):1062-1070.

13. Héritier F, Perret C, Fitting JW. Maximal sniff mouth pressure compared with maximal inspiratory pressure in acute respiratory failure. Chest 1991;100(1):175-178.

14. Terzi N, Corne F, Mouadil A, Lofaso F, Normand H. Mouth and nasal inspiratory pressure: learning effect and reproducibility in healthy adults. Respiration 2010;80(5):379-386.

15. Wen AS, Woo MS, Keens TG. How many maneuvers are required to measure maximal inspiratory pressure accurately? Chest 1997; 111(3):802-807.

16. Jung MC, Hallbeck MS. Quantification of the effects of instruction type, verbal encouragement, and visual feedback on static and peak handgrip strength. Int J Indust Ergonomics 2004;34(5):367-374. doi: 10.1016/j.ergon.2004.03.008.

17. Samuel D, Wilson K, Martin HJ, Allen R, Sayer AA, Stokes M. Ageassociated changes in hand grip and quadriceps muscle strength ratios in healthy adults. Aging Clin Exp Res 2012;24(3):245-250.

18. Horie J, Murata S, Hayashi S, Murata J, Miyazaki J, Mizota K, Horikawa E. Factors that delay COPD detection in the general elderly population. Respir Care 2011;56(8):1143-1150.

19. Cottereau G, Dres M, Avenel A, Fichet J, Jacobs FM, Prat D, et al. Handgrip strength predicts difficult weaning but not extubation failure in mechanically ventilated subjects. Respir Care 2015;60(8): 1097-1104.

20. Piriyapatsom A, Williams EC, Waak K, Ladha KS, Eikermann M, Schmidt UH. Prospective observational study of predictors of reintubation following extubation in the surgical ICU. Respir Care 2016;61(3):306-315. 